\title{
Eosinophilic Esophagitis: Diagnosis and Current Management
}

\author{
Teodora Surdea-Blaga ${ }^{1}$, Elvis Popovicii ${ }^{1}$, Mihaela Fadgyas Stănculete ${ }^{2}$, Dan Lucian Dumitrascu ${ }^{1}$, Carmelo Scarpignato ${ }^{3,4}$
}

1) 2nd Medical Department

Emergency Clinic Country

Hospital, Iuliu Hatieganu

University of Medicine and

Pharmacy, Cluj-Napoca,

Romania

2) Dept. Neurosciences,

Iuliu Hatieganu University of

Medicine and Pharmacy, Cluj-

Napoca, Romania

3) Department of Health

Sciences, United Campus of

Malta, Msida, MSD 9024,

Malta

4) Faculty of Medicine,

Chinese University of Hong

Kong, ShaTin, Hong Kong

Address for correspondence:

Dan Lucian Dumitrascu

2nd Medical Department

Iuliu Hatieganu University of

Medicine and Pharmacy

Cluj-Napoca, Romania

ddumitrascu@umfcluj.ro
Received: 20.01.2020

Accepted: 20.02.2020

\begin{abstract}
Eosinophilic esophagitis (EoE) is an eosinophil-rich, Th2 antigen-mediated disease of increasing worldwide prevalence. Originally considered common in children and young adults, it can be seen at any age, with the highest prevalence between 30 and 40 years. Symptoms reflect esophageal dysfunction, and typical endoscopic pictures consist of rings, furrows, exudates and edema. Progressive disease leads to pathologic tissue remodeling, with ensuing esophageal rigidity and loss of luminal diameter caused by strictures. The definitive diagnosis is histological (at least 15 eosinophils/HPF, high power field), upper gastrointestinal endoscopy with multiple esophageal biopsies being mandatory. Current therapeutic options include dietary and pharmacologic treatments. Despite being successful in a high proportion of patients, elemental diet has multiple disadvantages. Therefore, a step-up approach (using a two-, four- and six food elimination diets) is preferred, being globally effective in up to $79 \%$ of cases and avoiding unnecessary restrictions. Drug therapy relies on proton pump inhibitors and topical corticosteroids. Esophageal dilation may be required to increase luminal patency, leading to immediate symptomatic improvement in $95 \%$ of EoE patients, who have strictures or narrow caliber esophagus. The chronic nature of the disease necessitates long-term therapy. In this review, current diagnostic and treatment options are discussed and a treatment algorithm is proposed.
\end{abstract}

Key words: eosinophilic esophagitis - diagnosis - treatment.

Abbreviations: CAPN14: Calpain-14; EoE: eosinophilic esophagitis; EREFS: exudates, rings, edema, furrows, and strictures; GERD: gastro-esophageal reflux disease; HPF: high power field; HRQoL: health-related quality of life; PPI: proton pump inhibitor; PPI-REE: esophageal eosinophilia responding to PPIs; SFED: six-food elimination diet; TSLP: thymic stromal lymphopoietin.

\section{INTRODUCTION}

Eosinophilic esophagitis (EoE), a chronic, immunemediated disease, characterized by eosinophilic infiltration at the esophageal level, producing esophageal dysfunction, has raised great interest in recent years. It now represents a major differential diagnosis when patients present with dysphagia, food impaction and symptoms of gastroesophageal reflux [1, 2]. There is an approximately $3: 1$ male-to-female predominance, male gender being a strong risk factor for developing EoE $[1,3]$. A microscopic assessment of the esophageal endoscopically taken biopsies showing at least 15 eosinophils/HPF is required to establish a diagnosis of EoE in a suggestive clinical setting [1]. The number of EoE publications before 2000 was about $0-1$ per year and has increased to more than 200 publications in 2013. Eosinophilic esophagitis is a rapidly increasing disease, in incidence and also in prevalence [4] and generates an estimated annual burden of approximately 1,4 billion dollars in the United States of America [5]. A recent study on Japanese patients showed that EoE is a mild disease with a slow pattern of progression [6]. Being initially an inflammatory condition, over time, EoE progresses to a fibrostenotic disease [7]. According to the latest EoE published guideline, diet, proton pump inhibitors (PPIs) and topical steroids are the current treatment options for these patients [1].

\section{EPIDEMIOLOGY}

The first report of a patient with EoE was published in 1978 by Landres et al. [8]. Since then, various case reports 
with different terminology (such as idiopathic EoE, allergic esophagitis, primary EoE, etc.) have been reported. In 1993, Attwood et al. were among the first to characterize the disease [9]. The incidence and prevalence of EoE have risen rapidly in the last years. Nevertheless, it is not known if the everincreasing number of EoE cases is due to a real increase in incidence or is the result of better recognition $[10,11]$. In addition, there are reports showing that the number of biopsies almost doubled in a period of 15 years [12]. The reported incidence of EoE varies from 1 to 20 new cases per 100.000 inhabitants per year with a mean value of 7 and the prevalence ranges between 13 and 49 cases per 100,000 inhabitants [1]. Epidemiological data reported by several European studies are summarized in Table I.

At variance from a commonly held idea that EoE is a disease mainly diagnosed in children and younger adults, any age can be affected by EoE, with the highest prevalence between 30 and 40 years, male gender being the most frequently involved $[13,17]$. From a geographic point of view, reports of EoE cases and studies covering developed countries prevail upon those published from developing countries, no report being available from Africa [18]. Caucasians have an older age than African-American subjects and develop dysphagia more frequently. However, race is not significantly associated with atopic diseases, gender or clinical symptoms, other than dysphagia. Esophageal rings were reported more frequently in Caucasians [19].

\section{PATHOPHYSIOLOGY}

The pathogenesis of EoE has not been yet fully elucidated. Since, according to early reports, the histologic picture of EoE improved following restriction of dietary antigens [20], and symptoms reappeared after reintroduction of the triggering dietary components, the condition was considered to be an allergic disease [21]. Furthermore, $70 \%$ of pediatric population and half of the adults diagnosed with EoE are positive to skin prick testing and serum testing to food antigens [22]. In addition, patients with EoE have often other atopic disorders such as rhinitis, asthma or atopic dermatitis $[1,23]$. Aeroallergens seem to be involved, as spring and summer cases outnumber the cases diagnosed in the fall or winter [24], possibly due to sensitization to food allergens derived from plants, which cross-react with pollens [23]. Whether EoE is an IgE-mediated disease, or an IgG4-associated condition is still a matter of debate [25].

More recent studies identified susceptibility genes associated with disease development. Squamous epithelial cells of the esophagus have a high expression of Calpain-14 (CAPN14), an intracellular protease involved in cytoskeletal dynamics, cell-cycle progression, and gene expression. The CAPN14 gene is positioned in an epigenetic hotspot regulated by IL-13, a Th2 cytokine overexpressed in patients with EoE. Polymorphism of this gene (the variant at rs6736278) increases the risk of EoE, by impairing epithelial barrier function [26]. Esophageal epithelial cells also produce thymic stromal lymphopoietin (TSLP), which induces Th2-type immune response. Genetic variants at 5q22 encoding TSLP have been associated with allergic diseases such as asthma, allergic rhinitis, and EoE [27]. Approximately $1 / 3$ of patients with EoE have other autoimmune conditions, including celiac disease, Crohn's disease, ulcerative colitis, rheumatoid arthritis, etc. A recent study reported a common locus (16p13) inducing a high risk for both EoE and non-allergic, immune-mediated diseases. This region encodes for the genes expressed in immune cells and esophageal epithelial cells [28]. Environmental factors, including the ones experienced in early life are involved in the etiology of the disease. An overly hygienic environment, antibiotic and PPIs use, cesarean delivery influence the hostmicrobiome balance and might increase the risk of EoE [29].

Thus, in a genetically susceptible person, with an impaired epithelial barrier function, such as a patient with gastroesophageal reflux disease (GERD), food and microbiota antigens penetrate underneath the epithelium and induce a Th2 type immune response in the esophagus [30]. This type of immune response plays an important role in EoE pathogenesis and was suggested by the presence of Th2 type cytokines (especially IL-5 and IL-13) in esophageal mucosa of patients with EoE [31]. IL-5 stimulates eosinophil production, and IL-13 increases eotaxin-3 production by esophageal epithelial cells, increasing secondary eosinophil accumulation [32]. Activated eosinophils release granular proteins, which

Table I. Epidemiology of eosinophilic esophagitis in Europe

\begin{tabular}{|c|c|c|c|c|c|c|}
\hline Paper & Region/ Country & Period studied & Age (years) & Gender & $\begin{array}{l}\text { Incidence } / 100,000 \\
\text { inhabitants }\end{array}$ & $\begin{array}{l}\text { Prevalence } \\
/ 100,000 \\
\text { inhabitants }\end{array}$ \\
\hline $\begin{array}{l}\text { Hrutz et al. } \\
{[13]}\end{array}$ & $\begin{array}{l}\text { Olten County, } \\
\text { Switzerland }\end{array}$ & 1989-2009 & $9-77$ & $76 \%$ males & $\begin{array}{l}2.45 \text {; annual incidence } \\
\text { increased in the last } 6 \text { years } \\
(4.4-7.4)\end{array}$ & 42.8 \\
\hline $\begin{array}{l}\text { Arias AJL et } \\
\text { al. } 2013[14]\end{array}$ & Spain & $\begin{array}{l}\text { January } 2005 \text { - } \\
\text { December } 2011\end{array}$ & $29.480 \%<40$ years & Male/female: $19 / 1$ & 6.37 & 44.6 \\
\hline $\begin{array}{l}\text { Giriens B et } \\
\text { al. } 2015 \text { [15] }\end{array}$ & $\begin{array}{l}\text { Canton of Vaud, } \\
\text { Switzerland }\end{array}$ & 1993-2013 & $\begin{array}{l}3-81 \text { (the mean age } \\
\text { at diagnosis } 41+/- \\
16 \text { years) }\end{array}$ & $\begin{array}{l}\text { incidence was almost } \\
3 \text { times higher in } \\
\text { males than in females }\end{array}$ & $\begin{array}{l}0.16 \text { in } 2004 ; 6.3 \text { in } 2013 \\
10.6 \text { times higher between } \\
2010-2013 \text {, compared with } \\
1993-2009 \text { period }\end{array}$ & 24.1 in 2013 \\
\hline $\begin{array}{l}\text { Dellon ES et } \\
\text { al. } 2015 \text { [12] }\end{array}$ & Denmark & $1997-2012$ & Mean age $=48$ years & $71 \%$ males & $\begin{array}{l}19.5 \text { increase between } 1997 \\
\text { and } 2012(0.13 \text { to } 2.6)\end{array}$ & 13.8 in 2012 \\
\hline $\begin{array}{l}\text { Warners M et } \\
\text { al. } 2017 \text { [16] }\end{array}$ & Netherlands & $1996-2015$ & 37.5 & $83 \%$ males & 0.01 in $1996 ; 2.1$ in 2015 & \\
\hline
\end{tabular}


break the epithelial barrier and injure the neurons, hence altering sensory and motor function of the esophagus. They also increase TGF- $\beta$ and periostin, which stimulate fibrosis, and over time determine tissue remodeling [33]. A synopsis of the current understanding of pathophysiology of EoE is presented in Fig. 1.

Novel pathogenetic concepts have recently been put forward [35]. From a gastroenterological standpoint, the most intriguing hypothesis relates to the use of antisecretory medications, especially the PPIs [36]. Studies have shown that some food allergens that ordinarily would be degraded by peptic digestion are not degraded when the $\mathrm{pH}$ of gastric fluid is raised. Other studies have shown that PPIs increase gastrointestinal mucosal permeability, which might facilitate the uptake of undegraded peptide allergens. In adult patients treated with antisecretory medications for 3 months, IgE antibody levels and new, food-specific IgE antibodies are elevated [36]. These findings provide a plausible mechanism whereby acid-suppressive medications, by interfering with the peptic digestion of food allergens and increasing mucosal permeability, might lead to the development of food allergy. And indeed, the time course of the introduction and subsequent widespread use and misuse of PPIs [37] with the emergence of EoE [15] fits well with the hypothesis that PPIs might play an etiological role.

While it is now clear that heritability of EoE is a complex issue, few studies have examined the interaction between identified genetic variants and environmental factors. Further research into the subgroups and epigenetics of EoE will promote a better understanding [38].

\section{CLINICAL MANIFESTATIONS}

Clinical presentation varies with age. In infants, feeding problems such as gagging, food refusal and later introduction of solid food are observed. Failure to thrive, described as inadequate growth or incapacity to maintain growth, is another manifestation reported in infants and small children [39-41]. Gastro-esophageal reflux disease symptoms or vomiting were reported in young children with EoE, whereas older children developed dysphagia and food impaction [3]. In the study of Ettyreddy et al. [42] EoE was the most frequent cause for food impaction (in more than $70 \%$ of cases).

Dysphagia represents the most common symptom in adults. Remedios et al. [43] found that any adult patient with EoE had a history of solid food dysphagia. In a retrospective study, Dellon et al. [44] compared symptoms and other parameters in patients with EoE or GERD. They noticed that all EoE patients experienced more often dysphagia and food impaction, whereas the group of GERD patients reported heartburn and abdominal pain as main symptoms. Heartburn was common in both groups: $46 \%$ in EoE patients vs. $56 \%$ in GERD patients $(\mathrm{p}=0.009)$ [44]. Patients with dysphagia, in whom EoE was diagnosed, tended to be younger than those with dysphagia without EoE ( $42 \pm 15$ years vs. $61 \pm 15$ years) [45]. Studies from Western countries reported more cases of food impaction compared to Asian studies [46].

There are no clinical symptoms that can predict EoE, but dysphagia was significantly more often reported in the EoE positive patients [47]. A median delay of 6.5 years was reported from the first esophageal symptoms to the identification of EoE [48] and a median delay of 1 year was reported from the first presentation at hospital to the diagnosis [49].

Patients with EoE have often other allergic disorders. In the study of Mackenzie et al. [45] the prevalence of EoE was higher in those complaining of food allergies, or asthma. In another study of 562 patients who had confirmed EoE, two-thirds of patients presented with other allergic diseases [3].

Eosinophilic esophagitis impairs the health-related quality of life (HRQoL) of patients. Children with EoE evaluated in a tertiary care program experienced psychosocial adjustment and coping problems [50]. Pediatric patients have reduced QoL and persistent symptoms even 15 years after presentation [51]. Mukkada et al. [52] reported that EoE has a significant impact on HRQoL, resulting in disruption to and restrictions on daily life for patients, their caregivers, and, in some instances, their families. Current pharmacologic and dietary treatments improve the HRQoL of patients [52]. Patients with EoE and

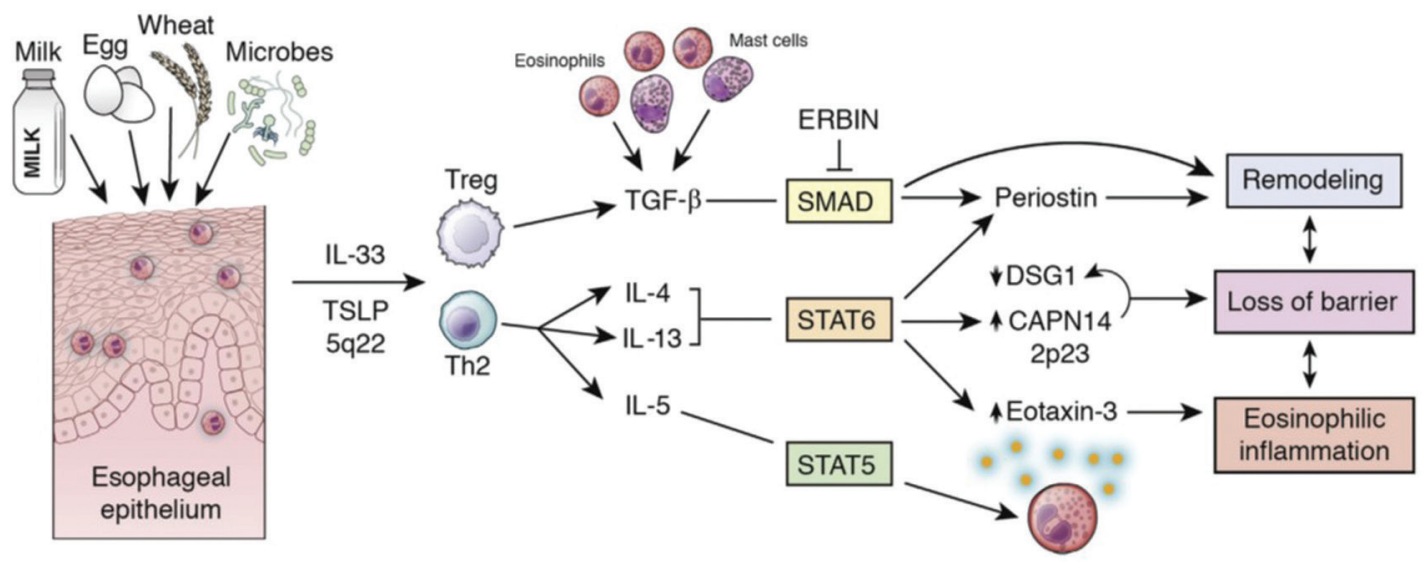

Fig. 1. Pathophysiologic overview of EoE. Environmental factors, including foods and the microbiome, interact with the esophageal epithelium to elicit production of the proatopy cytokines IL-33 and TSLP. Activated T regulatory and T helper type 2 cells secrete bioactive cytokines including TGF- $\beta$, IL-4, IL-13, and IL-5, which elicit barrier disruption, tissue remodeling, and eosinophilic inflammation (Reproduced, with permission, from O'Shea et al. 2018 [34]) 
esophageal dysfunction try to improve their QoL by changing their eating habits. They develop behavioral adaptations (such as learning to eat slowly and cautiously) according to their symptoms [48].

\section{DIAGNOSIS}

Symptoms such as dysphagia or food impaction in adults, or feeding problems in children, should raise the concern of EoE. The definitive diagnosis is histological. Therefore, upper GI endoscopy with multiple esophageal biopsies is mandatory. At least 15 eosinophils/HPF (high power field) are required on esophageal biopsies to establish a diagnosis of EoE. Barium swallow can be useful, providing information complementary to endoscopy [18]. It can detect rings, stenoses or sub-stenosis, also showing the length and diameter of the esophageal body, besides being mandatory before a dilation procedure. The measurement of the maximum esophageal diameter represents a reliable parameter to evaluate the response to treatment [53].

Eosinophilic esophagitis and GERD are different entities and may coexist, either unrelated or interacting bidirectionally $[1,54]$. Esophageal $\mathrm{pH}$ recording can show an abnormal esophageal exposure in some patients, but $\mathrm{pH}$-impedance monitoring almost always finds significantly lower basal impedance levels in the distal, mid and proximal esophagus compared to healthy controls. Whereas baseline impedance decreases from proximal to distal in healthy subjects, no such gradient was seen in EoE patients [55]. Since both animal and human studies have shown that esophageal impedance correlates with the transepithelial resistance measured in vitro (that in its turn is correlated with intercellular spaces) [56], baseline impedance is now considered a marker of esophageal mucosal integrity, which appears therefore markedly reduced in patients with EoE [54]. The dilation of intercellular spaces can explain why patients with EoE are hypersensitive to acid perfused in the esophagus, feeling acid earlier than those with concomitant GERD or healthy volunteers [57]. Therefore, even physiologic acid reflux may trigger symptoms in these patients.

There is no need for routine manometry since it shows non-specific results [58]. High-resolution esophageal manometry showed that $35-37 \%$ of EoE patients have an abnormal esophageal motility pattern $[59,60]$. The most frequent diagnoses were of weak peristalsis and frequent failed peristalsis. Although motility disorders were more frequent in EoE patients than in controls, the prevalence and type were similar to those observed in GERD patients [59]. Pan-esophageal pressurization was present in $17 \%$ of cases, while compartmentalized pressurization was present in $19 \%$ of patients [59]. These patterns were resolved after therapy in $86 \%$ of the cases [60].

After a (manometric and/or radiologic) diagnosis of achalasia and a food impaction history, esophageal biopsies are mandatory to exclude EoE [61]. It is important to realize that there are other causes of eosinophilic infiltration of the esophagus such as GERD, which is characterized by a low eosinophil count, usually under 5 eosinophils/HPF [1], Barrett disease, drug-induced esophagitis, parasitic infections, vasculitis and Crohn's disease [62]. In a few cases, people belonging to the same family of patients with EoE presented with esophageal symptoms and molecular, immunehistochemical, genetic patterns that resembled EoE, but without esophageal eosinophilia. This clinical entity is often referred to as EoE-like disease [63].
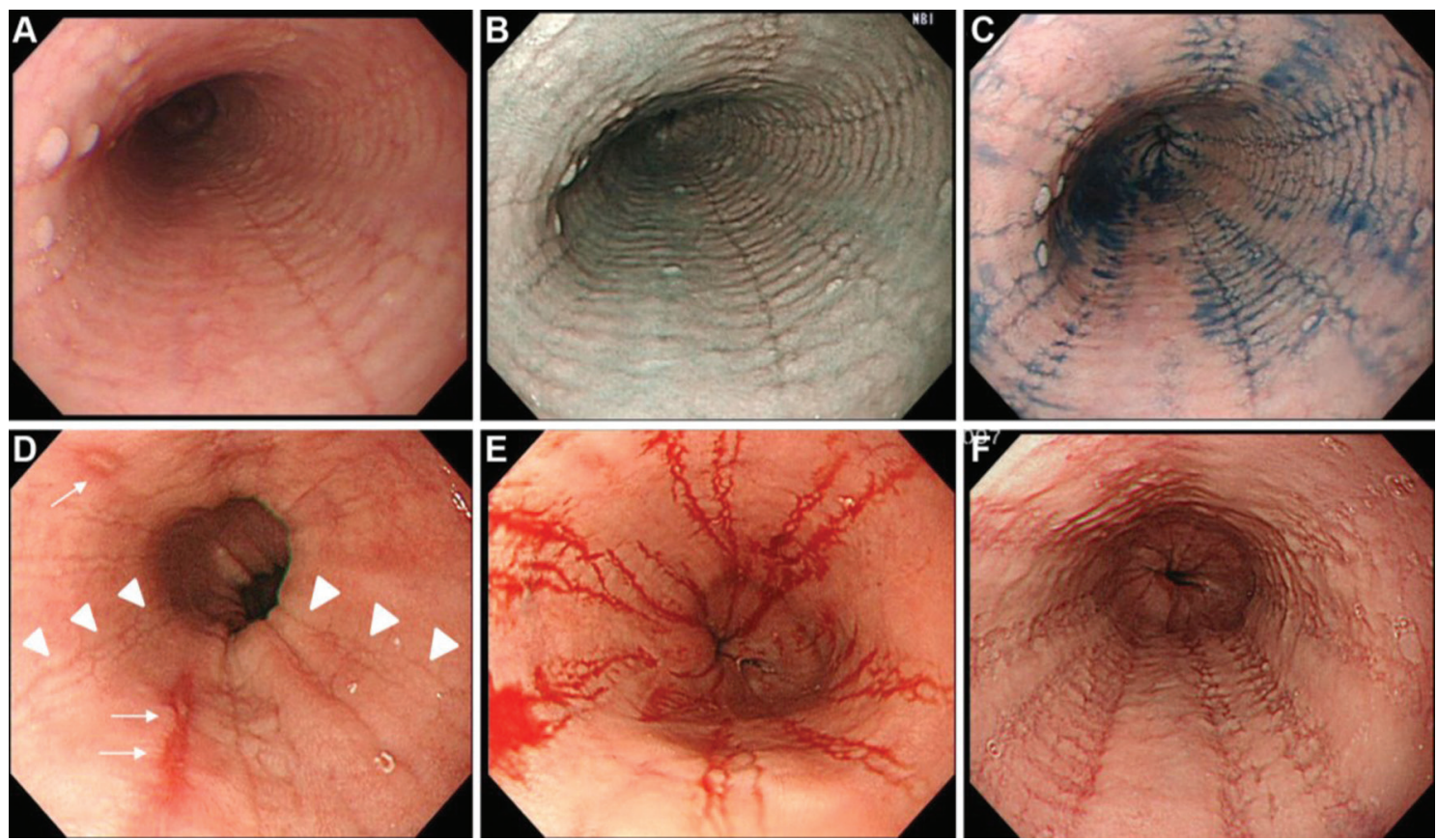

Fig. 2. Endoscopic findings in eosinophilic esophagitis: linear furrows run along the longitudinal axis of the esophagus. A) White light image. B) Narrow-band imaging. C) Indigo carmine-sprayed image. D) Linear erosion with reflux esophagitis (white arrows) is distinguishable from linear furrows with $\mathrm{EoE}$ (white arrow heads). E) Double line or fissure-like furrows are easily recognized when in contact with blood after esophageal biopsies are obtained. F) Cobble-stone like appearance is present in the linear furrows in severe cases (Reproduced, with permission, from Abe et al., 2017 [71]). 


\section{Endoscopy}

Younger patients have either a normal aspect of the esophagus or inflammatory changes, and older patients have more classic endoscopic findings. In children, normal aspect, white exudates, erythema and erosive esophagitis were often found, while in adults, esophageal narrowing, esophageal strictures, crepe-paper mucosal alterations and rings were the most common findings $[43,44]$.

A meta-analysis found that linear furrows (48\%), esophageal rings (44\%) and pallor/decreased vascularization (41\%) are the most characteristic endoscopic findings [64]. Plaques, strictures, narrow caliber esophagus, are less frequent (Fig. 2). Although the endoscopic features raise clinical suspicion, the definitive diagnosis always requires esophageal biopsies with histology [64].

Hirano et al. [65] proposed a novel classification for EoE, in order to standardize endoscopic assessment among endoscopists. There was a good agreement between observers for the four major features of EoE namely rings (fixed, concentric rings), furrows (vertical lines), exudates (white spots or plaques) and edema (decreased vascular markings and mucosal pallor), but also for stricture and crepe-paper esophagus (mucosal fragility). Based on this novel classification, an endoscopic reference score EREFS (acronym for Exudates, Rings, Edema, Furrows, and Strictures) was proposed (Table II) with a maximum score of 9 points. Narrow-caliber esophagus and crepe-paper esophagus were excluded from EREFS [66]. Data regarding the use of this endoscopic classification to assess activity or remission of disease are so far conflicting [67]. This score is not routinely used by physicians in every-day practice [68].

Table II. Endoscopic score EREFS for grading eosinophilic esophagitis (from Hirano et al. [65])

\begin{tabular}{ll}
\hline Endoscopic change & Scoring \\
\hline Exudates & 0 - absent \\
& 1 - mild, $<10 \%$ of the esophageal surface area \\
& 2 - severe, $\geq 10 \%$ of the esophageal surface areas \\
& 0 - absent \\
Rings & 1 - mild, subtle circumferential ridges \\
& 2 - moderate, distinct rings \\
& 3 - severe, rings that impair passage of a standard \\
& adult diagnostic endoscope \\
& 0 - absent \\
& 1 - present, loss of vascular markings \\
& 0 - absent \\
& 1 - mild, present but without visible depth \\
& 2 - severe, visible depth or mucosal indentation \\
Furrows & 0 - absent \\
& 1 - present
\end{tabular}

\section{Peripheral blood eosinophilia}

Half of the patients have peripheral blood eosinophilia [69]. A relation between the number of circulating eosinophils and the eosinophils that infiltrate the esophagus has been established. Allergic patients who have an esophagus infiltrated with eosinophils have a higher count of blood eosinophils than allergic patients without EoE [70].

\section{Esophageal biopsies}

Because inflammatory changes in EoE are frequently patchy, the probability of detecting EoE increases with the number of specimens obtained [72]. The European guideline on EoE recommends at least 6 biopsies from proximal and distal halves of the esophagus [1]. It is preferable to take biopsies from abnormal appearing mucosa, as exudates and longitudinal furrows hold the highest number of eosinophils. It is worth mentioning that up to 1/3rd of children and adults with EoE have a normal macroscopic esophageal mucosa. Therefore, if there is a clinical suspicion, biopsies should be taken [64]. In addition, specimens from antrum and duodenum are always required to rule out eosinophilic gastroenteritis, a secondary cause of eosinophilic infiltrate in the esophagus [1].

The diagnosis of EoE requires at least 15 eosinophils/ HPF. This threshold allows to differentiate EoE from other esophageal inflammatory diseases [1]. Recently, new methods, such as cytosponge or ultrathin unsedated transnasal gastroscopy, have been proposed to monitor disease activity and to assess response to therapy $[73,74]$.

\section{TREATMENT}

The treatment can be summarized in the three Ds: diet, drugs and dilation [75]. Currently, the first suggested step is a trial of PPIs. If the patient does not respond, either topical corticosteroids or diet are proposed, taking into consideration the age of the patient (young adults show poor adherence to diet), the severity of symptoms and the patient's lifestyle and preferences. When symptoms are severe, topical steroids are preferred. Patients, who develop fibrostenotic abnormalities are referred to endoscopic dilation [1].

\section{Dietary options}

There are three types of diet: elemental diet which consists of total elimination of food allergens using exclusively an amino acid-based formula, elimination of specific food allergens after skin allergy testing and empiric 6 food elimination diet which involves removing foods known by their potential allergenic characteristics [76].

Peterson et al. [77] showed that after 4 weeks on the elemental diet, there was a substantial histologic improvement in most cases. However, symptoms and endoscopic fixed strictures did not improve. Authors concluded that EoE in adults is substantially triggered by foods [77]. The elemental diet has multiple disadvantages such as avoiding all table food, high cost, unpleasant taste, social limitations, inducing also negative psychological effects. Thus, in the most cases, it is limited to children with EoE. Indeed, the European Guideline recommends considering elemental diet only after trying and failing with medical treatment and/or elimination diet [1].

A more targeted approach in dealing with allergy has been developed. First, specific food allergens are searched, using skin allergy testing [78]. Three types of allergy tests are used in EoE: skin prick testing, atopy patch testing and measurement of serum food-specific IgE [76]. The skin prick testing combined with patch testing has proved to be capable of identifying allergic foods that are involved in the pathogenesis of EoE [79]. However, as shown by a meta-analysis [78], the 
combined effectiveness does not exceed 50\%. Using a skin test is therefore questionable and developing a dietary therapy only on skin test results in adults is not recommended [80].

Using the six-food elimination diet (SFED), patients are advised to avoid common allergens such as milk protein, soy, eggs, wheat, peanuts/tree nuts, and seafood. In one study, legumes, rice, and corn were also excluded, given the characteristics of the population studied [81]. Six-food elimination diet significantly ameliorates symptoms and improves endoscopic and histopathologic appearance of EoE [82]. Studies looked also at 2-food and 4-food elimination diets. Four-food elimination diet induced remission in 54\% of adult patients [83]. Moreover, SFED was effective in almost $1 / 3$ of the non-responders to the previous strategies. Globally, a $72 \%$ combined efficacy was reported when using both dietary approaches [83]. Knowing that milk and wheat/gluten are the main allergens incriminated in the EoE development, Molina-Infante et al. [84] performed a prospective study which began with 6 weeks of 2 -food elimination diet. Remission was achieved in $43 \%$ of patients, with no differences between ages. Non responders were gradually taken to four-food elimination diet and 6-food elimination diet. Remission with 4 -food elimination diet and SFED was observed in 60\% and $79 \%$ of cases, respectively. In order to avoid unnecessary restrictions, to save endoscopies and to shorten the time to the diagnosis, the authors suggested a step-up approach with an early identification of patients that respond to an empiric diet with few food allergens [84]. Despite rational, long term adherence to this type of diet in real life is below $60 \%$, the influencing factors being diet effectiveness, social situations, and diet-related anxiety [85].

Many physicians still believe that the food groups included in empiric diets are removed from the patients' regular diet indefinitely. In responders to any empiric 6-week diet, all food groups should be reintroduced individually, with an endoscopy performed following each food challenge. The final goal is to provide a personalized maintenance therapy, with long-term removal solely of food triggers, namely, foods proven to induce esophageal inflammation after individual reintroduction [86].

\section{Proton pumps inhibitors}

Until recently, patients with esophageal eosinophilia responding to PPIs (PPI-REE) were excluded from EoE. Given the fact that EoE and PPI-REE are indistinguishable even at histological, molecular and genetic level, the last European guideline includes PPI-REE in the spectrum of EoE [1].

It is well known that PPIs display several non-antisecretory activities [87], of which the mucosal protective and antiinflammatory ones are the most relevant. Several mechanisms underly the anti-inflammatory action of PPIs: antioxidant effects and effects on inflammatory cells, endothelial and epithelial cells and gut microbiota [88]. The anti-inflammatory effects of PPI therapy rather than acid suppression alone may be responsible for the observed clinical and histologic improvement through inhibition of the Th2-allergic pathway. Indeed, like topical corticosteroids, PPIs down-regulated cytokine expression (eotaxin-3/Th2-cytokine) [89]. The mucosal protective activity of PPIs was studied by investigating their effect on esophageal mucosal barrier in patients with
PPI-REE or EoE [90]. As already discussed, the integrity of the esophageal mucosa is impaired in both these patients, allowing transepithelial transport of small molecules and allergens. Indeed, in vitro studies from esophageal biopsies found that transepithelial electrical resistance is reduced and intercellular spaces are dilated. PPI therapy partially restores mucosal integrity in patients with PPI-REE, but not in those with EoE [90]. This normalization of dilated intercellular spaces is similar to that observed in patients with GERD [91].

Both retrospective and prospective studies reported histological remission after a 8 -week course treatment with PPIs, with rates of remission varying from 33 to $50 \%$, depending on the cut-off used to define remission $(<5$ to 7 eosinophils/HPF or $<15$ eosinophils/HPF) $[92,93]$. Patients with established GERD have higher chances to respond to PPIs. In addition, symptom improvement is common with PPI therapy despite persistent eosinophilic infiltration [94].

A meta-analysis of 33 studies (431 adults and 188 children) found an overall histologic remission and clinical response of $50.5 \%$ and $60.8 \%$, respectively [95]. No differences were observed regarding the study population (children vs. adults) (Table III), the type of publication, or its quality. However, PPIs appeared more effective, albeit non significantly, in prospective studies rather than in retrospective ones $(52.6 \%$ versus $39.1 \%$ ). PPI therapy was more effective when given twice daily (55.9\%) compared to once daily (49.7\%) and when administered to patients with abnormal esophageal exposure to acid (success rate $65.4 \%$ vs $49.3 \%$ in those with normal esophageal $\mathrm{pH}$-metry). Here again, these differences fell short of statistical significance [95]. To induce clinical remission in adults, the European guideline recommends a dose of 20-40 mg of omeprazole or equivalent, twice daily, for 8 weeks [1]. To evaluate PPI-induced histologic improvement in patients with EoE, multiple mucosal specimens are generally needed. However, 4 biopsies (from the lower and middle esophagus) may be sufficient [96]. In responders, PPIs can also be used for maintenance by using the lowest effective dose [1].

Table III. Histologic remission rates and Clinical Remission/Improvement for PPI therapy in patients with EoE (compiled from Lucendo et al. [95])

\begin{tabular}{lllll}
\hline Patients & $\begin{array}{l}\text { Histologic } \\
\text { Remission (\%) }\end{array}$ & $\mathrm{I}^{2}(\%)$ & $\begin{array}{l}\text { Clinical } \\
\text { Response (\%) }\end{array}$ & $\mathrm{I}^{2}(\%)$ \\
\hline Overall & $50.5(42.2-58.7)^{*}$ & 67.5 & $\begin{array}{l}60.8 \\
(43.4-72.2)^{*}\end{array}$ & 80.2 \\
& & & $\begin{array}{l}56.2 \\
(41.4-70.4)^{*}\end{array}$ & 78.3 \\
Adults & $49.6(40.1-59.2)^{*}$ & 65.5 & & 84.9 \\
& & & \\
Children & $54.1(37.7-70.0)^{*}$ & 69.6 & $(43.4-83.6)^{*}$ & \\
\hline
\end{tabular}

${ }^{*} 95 \%$ Confidence intervals. The high $\mathrm{I}^{2}$ statistic values show the high heterogeneity of results among the different retrieved studies

In summary, due to their safety profile, ease of administration, and high response rates (up to $60 \%$ clinically), PPIs have been considered as a first-line pharmacologic treatment for EoE by the Italian PPI Position Paper [97]. Some studies show that patients with EoE, responsive to topical steroids and diet, also respond to PPI treatment $[98,99]$. However, while topical steroid therapy should be selected as second-line treatment, owing to long-term safety concerns, 
simple dietary interventions are safe and inexpensive and, provided adherence by motivated patients be high, could be attempted before any pharmacologic therapy.

\section{Corticosteroids}

More than 20 years ago, oral corticosteroids were used to alleviate severe reflux symptoms in patients with EoE not responsive to PPIs and prokinetics. Clinical and histological improvement was observed after short courses (4 weeks) of methylprednisolone [100]. The use of oral corticosteroids is limited, however, by the high frequency (40\%) of adverse effects [101]. Topical corticosteroids are nowadays the mainstay of EoE therapy [1]. Randomized trials and meta-analyses confirm their efficacy in inducing histologic remission in EoE [102, 103]. Adverse events of topical corticosteroids do also occur, especially esophageal asymptomatic candidiasis (number needed to harm of 9) [104].

In the meta-analysis of Murali et al. [102], topical corticosteroids proved to be effective in inducing histological remission. However, the improvement in clinical symptoms did not reach statistical significance [102]. In the meta-analysis conducted by Sawas et al. [103], compared to the control group (placebo or PPI), topical steroid treatment achieved both symptomatic improvement (OR: 3.03, 95\% CI: 1.57-5.87) and histological remission (OR: 13.66, 95\% CI: 2.65-70.34).

Current steroid formulations used in the treatment of EoE are designed for airway delivery, and patients are instructed to swallow the various formulations: suspensions, puffs from inhalers, viscous slurry or orodispersible tablets [1]. Physicians should prefer the ones that offer the longest contact time between the drug and esophageal mucosa (for example viscous formulations are prefered to swallowed puffs), since this parameter was correlated with a higher reduction in eosinophils count [105]. In 2016, Miehlke et al. [106] reported that both regimens with budesonide (1 mg twice daily or 2 $\mathrm{mg}$ twice daily) were equally effective; the effervescent tablet formulation was preferred by $80 \%$ of patients. These two formulations (orodispersible tables and viscous suspensions) showed the highest histologic remission rates [1].

Fluticasone (440 to $880 \mu \mathrm{g}$ twice daily) or budesonide (1-2 $\mathrm{mg}$ twice daily) for 8 weeks can be used to induce remission. Although long-term therapy with topical corticosteroids is considered effective in maintaining remission, there are no general recommendations regarding the doses or the duration of treatment, as yet [1]. In one study, 28 adult patients received either budesonide $0.5 \mathrm{mg} /$ day or placebo for 50 months, and at the end of follow-up, only $36 \%$ of patients were in complete histological remission [107]. The dose was however quite small, and this might have diminished the effectiveness of the treatment [1]. In a similar study in children, a constant dose of fluticasone (2 puffs to swallow twice a day; 2-4-year old: $44 \mu \mathrm{g} /$ puff; 5-11-year old: $110 \mu \mathrm{g} /$ puff; and $\geq 12$-year old: $220 \mu \mathrm{g} / \mathrm{puff})$ for 24 months, induced histological remission in $60 \%$ of patients [108]. A comparison between fluticasone and budesonide showed that about half of the patients had a histological response to treatment $(<15$ eosinophils/HPF), while clinical response was reported in $2 / 3$ of the patients, with no difference in the response rate between fluticasone and budesonide [109].
One small trial in children evaluated ciclesonide, a topical glucocorticoid with less systemic absorption than fluticasone and showed that symptoms, as well as eosinophil counts, significantly decreased after 2 months of treatment [110]. Ciclesonide is a "pro-soft drug", which is converted to an active metabolite (desisobutyryl-ciclesonide) in the lungs. The anti-inflammatory effect of desisobutyryl-ciclesonide is much higher than ciclesonide, and therefore, the local effect of the metabolite is higher with lower systemic side effects [111]. Further studies with this interesting corticoisteroid are obviously needed to select the best regimen for the treatment of EoE.

\section{Endoscopic dilation}

The chronic inflammation of the esophageal mucosa leads to tissue remodeling, fibrosis and a change in esophageal caliber. Narrow caliber esophagus and fixed rings may indicate fibrous stricture formation. The risk factors for esophageal strictures are patient age and longer symptom duration [112, 113]. At a diameter $<13 \mathrm{~mm}$, dysphagia occurs, and a diameter $<17 \mathrm{~mm}$ can determine food impaction [69]. One study reported strictures or fibrosis in $56 \%$ of 950 patients with EoE, and $56 \%$ of these required dilation [114]. These patients are usually more refractory to steroid treatment [113] and require repeated endoscopic dilations.

Esophageal dilation can be performed with either a balloon or a Savary dilator. Both devices are useful; however, the tightness and length of the stricture determines which method should be used. If the stricture is short $(1-2 \mathrm{~cm})$, a balloon dilator is ideal, whereas a Savary dilator can be passed through a longer stretch of a narrowed esophagus. To date, no head-to-head comparison has been conducted to conclude that one method is better than the other [115]. EndoFLIP (endo Functional Luminal Imaging Probe) can be a helpful adjunctive tool in both stricture identification and assessment when planning for esophageal dilation in adults since esophageal distensibility (evaluated with this device) can improve after treatment with either diet or medication [116].

Endoscopic dilation leads to immediate symptomatic improvement in $95 \%$ of EoE patients who have strictures or narrow caliber esophagus. Symptoms improvement after performing endoscopic dilation shows that tissue remodeling contributes substantially to symptom generation in EoE [116] Since dilation has no effect on the underlying eosinophil inflammation, repeated procedures are usually required to maintain symptoms in remission. Adding an effective EoE treatment (be it pharmacologic or dietary) reduces the need of further dilation [112].

There is evidence of an increased fragility in the inflamed esophagus of patients with EoE. A systematic review evaluated the presentation, management and outcomes of surgical interventions for esophageal perforation in these patients: of 76 esophageal perforation episodes in 70 individual patients, only eight episodes occurred after dilation. Most patients were treated conservatively, and recovery was uneventful [117]. Therefore, endoscopic dilation is a safe procedure, with a low rate of serious complications $(<1 \%$ perforation rate) and a short-term improvement of symptoms in most patients [118, 119]. The high rate of severe complications from dilation 
reported in early literature has not been reproduced in most recent series, with mild postprocedural chest pain as the most common side effect [112].

A suggested treatment algorithm is illustrated in Fig. 3. In contrast to the current guideline [1], our algorithm starts with diet, because it is a valid, efficient option for a good number of patients [84].

\section{Other treatments}

One small case series documented a clinical and histologic response to azathioprine or 6-mercaptopurine in steroiddependent EoE subjects [120].

Despite a theorical rationale, sodium cromoglycate (mast cell stabilizer) and antihistamines ( $\mathrm{H}_{1}$-receptor antagonists) have all provided disappointing results [1]. Montelukast (a leukotriene D4 receptor antagonist) was found not superior to a placebo in maintaining remission induced by swallowed topical steroids and the compound marked OC000459 (an oral CRTH2 antagonist, effective against eosinophilic asthma) was associated with a significant improvement in symptoms, but not with normalization of esophageal eosinophil counts [121].

\section{Future treatments}

Several new drugs, especially monoclonal antibodies, are being developed to address the unmet medical needs of patients with EoE. Most are imported from other Th2-mediated allergic diseases and have the potential of modifying the natural history of the disease. However, this has to be demonstrated, as yet.

Anti-IL-5 therapies designed to target eosinophilic inflammation have been some of the most studied antiinflammatory biologic therapies in EoE. The main results of some small trials conducted with these monoclonal antibodies are summarized in Table IV. The drugs, especially the ones targeting Th2 axis showed the ability to moderately reduce eosinophilic esophageal infiltration. However, a parallel improvement of symptoms was not observed. After the disappointing results, obtained with the anti-IgE antibody omalizumab and IL-5 blockers (mepolizumab and reslizumab), anti-IL-13 drugs have shown some effectiveness. The IL-4 receptor antagonist dupilumab is the most promising option, but several molecules acting over different points at the intimate mechanisms leading to EoE are also potential therapies [121]. None of these investigational drugs is included in the latest EoE guideline, as a standard of care.

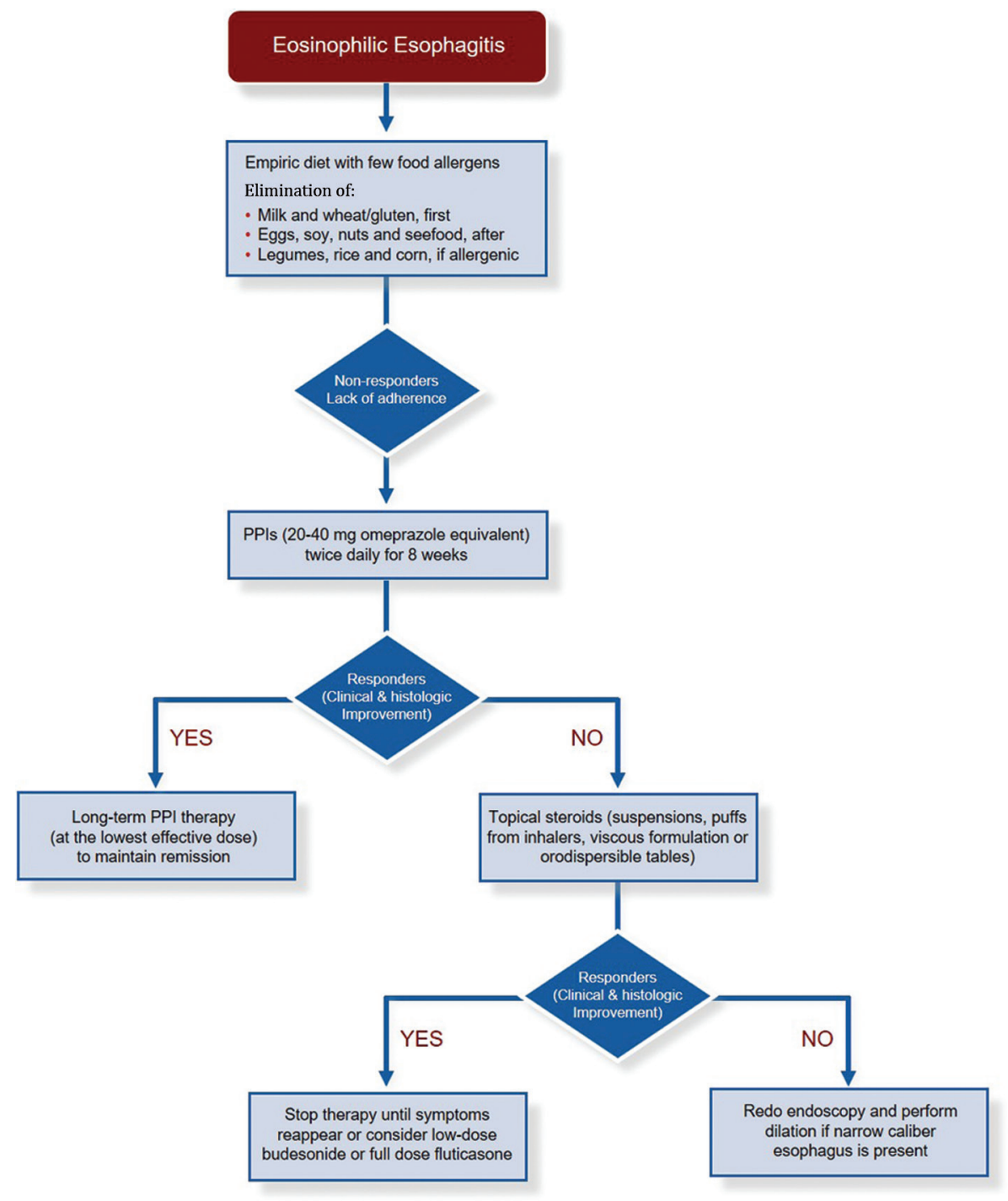

Fig. 3. Treatment options in patients with eosinophilic esophagitis. PPI: proton pump inhibitor 
Table IV. New potential treatments for eosinophilic esophagitis

\begin{tabular}{|c|c|c|}
\hline Study & Trial, drug and dosing & Main results \\
\hline Straumann A et al. 2010 [122] & $\begin{array}{l}\text { RCT, } \mathrm{n}=5 \text { (active arm), } \mathrm{n}=6 \text { (placebo arm) } \\
\text { Mepolizumab (anti-IL-5 monoclonal antibody), } \\
2 \text { infusions of } 750 \mathrm{mg}\end{array}$ & $\begin{array}{l}\text { - after } 4 \text { weeks marked reduction of mean oesophageal } \\
\text { eosinophilia, reduced TGF- } \beta 1 \\
\text { - only a minimum reduction of symptoms was observed }\end{array}$ \\
\hline Spergel JM et al. 2012 [123] & $\begin{array}{l}\mathrm{n}=226 \\
\text { Reslizumab (neutralizing antibody against IL-5) } \\
1,2 \text {, or } 3 \mathrm{mg} / \mathrm{kg} \text { reslizumab or placebo at weeks } \\
0,4,8 \text {, and } 12\end{array}$ & $\begin{array}{l}\text { - significant reduction of intraepithelial esophageal } \\
\text { eosinophil counts } \\
\text { - symptoms improvement but not different from the } \\
\text { placebo group }\end{array}$ \\
\hline Clayton F et al. 2014 [124] & $\begin{array}{l}\text { RCT, } \mathrm{n}=16 \text { (active arm), } \mathrm{n}=14 \text { placebo arm } \\
\text { Omalizumab (antibody against IgE) every } 2-4 \\
\text { weeks for } 16 \text { weeks }\end{array}$ & $\begin{array}{l}\text { - Omalizumab did not alter symptoms of EoE or eosinophil } \\
\text { counts in biopsy samples compared with placebo. } \\
\text { - esophageal tissue had high concentrations of IgG4 }\end{array}$ \\
\hline Hirano I et al. 2019 [125] & $\begin{array}{l}\text { Phase II trial, } \mathrm{n}=99 \text {; RPC } 4046 \text { monoclonal } \\
\text { antibody against IL-13, once weekly, } 16 \text { weeks } \\
180 \mathrm{mg}, 360 \mathrm{mg} \text { or placebo }\end{array}$ & $\begin{array}{l}\text { - RPC4046 reduced histologic and endoscopic features } \\
\text { compared with placebo } \\
\text { - clinical improvement did not reach statistical significance } \\
(\mathrm{p}=0.07)\end{array}$ \\
\hline
\end{tabular}

$\mathrm{RCT}=$ randomized controlled trial, $\mathrm{n}=$ number of subjects included, $\mathrm{IL}-5=$ interleukin 5 , IL-13= interleukin 13

\section{CONCLUSIONS}

Eosinophilic esophagitis is a chronic disease, genetically related with immune disorders, but also with allergic diseases. The incidence has been on the rise over the last ten years, and clinicians should be aware of this condition in patients with short term dysphagia or food impaction. Diagnosis and treatment of EoE are not always easy. Current therapeutic options, such as PPIs, topic corticosteroids, or elimination diet alleviate symptoms and induce histologic remission in most patients, but symptoms can reappear after discontinuing treatments and/or diet. Since progression to esophageal fibrosis and benign stenosis is possible, patients should be closely followed-up. Some new drugs (such as monoclonal antibodies against IL-13) appear promising, but the availability of novel therapies for EoE will require re-designing rational and realistic strategies for both remission and maintenance treatments. To overcome the limitations of current therapies, future approaches should be patient-centered and shared by all stakeholders involved in EoE.

Conflicts of interest: None to declare.

Authors' contributions: T.S.-B. E.P. M.F.S.: searched the literature and wrote the manuscript. D.L.D. and C.S. drafted the paper, wrote the manuscript and revised the final version of the paper. All authors approved the final version to be published, and agree to be accountable for all aspects of the work.

\section{REFERENCES}

1. Lucendo AJ, Molina-Infante J, Arias Á, et al. Guidelines on eosinophilic esophagitis: evidence-based statements and recommendations for diagnosis and management in children and adults. United European Gastroenterol J 2017;5:335-358. doi:10.1177/2050640616689525

2. James C, Assa'ad A. The Global Face of Eosinophilic Esophagitis: Advocacy and Research Groups. Clin Rev Allergy Immunol 2018;55:99105. doi:10.1007/s12016-018-8683-2

3. Spergel JM, Brown-Whitehorn TF, Beausoleil JL, et al. 14 years of eosinophilic esophagitis: Clinical features and prognosis.
J Pediatr Gastroenterol Nutr 2009;48:30-36. doi:10.1097/ MPG.0b013e3181788282

4. Dellon ES. Epidemiology of eosinophilic esophagitis. Gastroenterol Clin North Am 2014;43:201-218. doi:10.1016/j.gtc.2014.02.002

5. Jensen ET, Kappelman MD, Martin CF, Dellon ES. Health-care utilization, costs and the burden of disease related to eosinophilic esophagitis in the United States. American J Gastroenterol 2015;110:626632. doi:10.1038/ajg.2014.316

6. Sato H, Honma T, Nozawa Y, et al. Eosinophilic esophagitis in Japanese patients: A mild and slow-progressing disorder. PLoS One 2018;13:e0206621. doi:10.1371/journal.pone.0206621

7. Dellon ES, Kim HP, Sperry SL, Rybnicek DA, Woosley JT, Shaheen NJ. A phenotypic analysis shows that eosinophilic esophagitis is a progressive fibrostenotic disease. Gastrointest Endosc 2013;79:577-585. e4. doi:10.1016/j.gie.2013.10.027

8. Landres RT, Kuster GG, Strum WB. Eosinophilic esophagitis in a patient with vigorous achalasia. Gastroenterology 1978;74:1298-1301.

9. Attwood SE, Smyrk TC, Demeester TR, Jones JB. Esophageal eosinophilia with dysphagia. A distinct clinicopathologic syndrome. Dig Dis Sci 1993;38:109-116.

10. Whitney-Miller CL, Katzka D, Furth EE. Eosinophilic Esophagitis: A Retrospective Review of Esophageal Biopsy Specimens From 1992 to 2004 at an Adult Academic Medical Center. Am J Clin Pathol 2009;131:788-792. doi:10.1309/AJCPOMPXJFP7EB4P

11. Vanderheyden AD, Petras RE, DeYoung BR, Mitros FA. Emerging eosinophilic (allergic) esophagitis: increased incidence or increased recognition? Arch Pathol Lab Med 2007;131:777-779.

12. Dellon ES, Erichsen R, Baron JA, et al. The increasing incidence and prevalence of eosinophilic oesophagitis outpaces changes in endoscopic and biopsy practice:national population-based estimates from Denmark. Aliment Pharmacol Ther 2015;41:662-670. doi:10.1111/apt.13129

13. Hruz P, Straumann A, Bussmann C, et al. Escalating incidence of eosinophilic esophagitis: A 20-year prospective, population-based study in Olten County, Switzerland. J Allergy Clin Immunol 2011;128:13491350.e5. doi:10.1016/j.jaci.2011.09.013

14. Arias Á, Lucendo AJ. Prevalence of eosinophilic oesophagitis in adult patients in a central region of Spain. Eur J Gastroenterol Hepatol 2013;25:208-212. doi:10.1097/MEG.0b013e32835a4c95

15. Giriens B, Yan P, Safroneeva E, et al. Escalating incidence of eosinophilic esophagitis in Canton of Vaud, Switzerland, 1993-2013: a populationbased study. Allergy 2015;70:1633-1639. doi:10.1111/all.12733 
16. Warners M, de Rooij WE, van Rhijn BD, Verheij J, Smout AJ, Bredenoord AJ. Large Increase in Incidence of Eosinophilc Esophagitis Over the Last 20 Years in the Netherlands: Results from a Nationwide Pathology Database. Gastroenterology 2017;152:S862-S863. doi:10.1016/S00165085(17)32964-5

17. Kapel RC, Miller JK, Torres C, Aksoy S, Lash R, Katzka DA. Eosinophilic Esophagitis: A Prevalent Disease in the United States That Affects All Age Groups. Gastroenterology 2008;134:1316-1321. doi:10.1053/j. gastro.2008.02.016

18. Furuta GT, Liacouras CA, Collins $\mathrm{MH}$, et al. Eosinophilic esophagitis in children and adults: a systematic review and consensus recommendations for diagnosis and treatment. Gastroenterology 2007;133:1342-1363. doi:10.1053/j.gastro.2007.08.017

19. Sperry SL, Woosley JT, Shaheen NJ, Dellon ES. Influence of race and gender on the presentation of eosinophilic esophagitis. Am J Gastroenterol 2011;107:215-221. doi:10.1038/ajg.2011.342

20. Liacouras CA, Spergel JM, Ruchelli E, et al. Eosinophilic esophagitis: a 10-year experience in 381 children. Clin Gastroenterol Hepatol 2005;3:1198-1206. doi:10.1016/s1542-3565(05)00885-2

21. Kelly KJ, Lazenby AJ, Rowe PC, Yardley JH, Perman JA, Sampson HA. Eosinophilic esophagitis attributed to gastroesophageal reflux: improvement with an amino acid-based formula. Gastroenterology 1995; 109:1503-1512.

22. Aceves SS. Allergy Testing in Patients With Eosinophilic Esophagitis. Gastroenterol Hepatol 2016;12:516-518.

23. Simon D, Marti H, Heer P, Simon HU, Braathen LR, Straumann Al. Eosinophilic esophagitis is frequently associated with IgE-mediated allergic airway diseases. J Allergy Clin Immunol 2005;115:1090-1092. doi:10.1016/j.jaci.2005.01.017

24. Almansa C, Krishna M, Buchner AM, et al. Seasonal Distribution in Newly Diagnosed Cases of Eosinophilic Esophagitis in Adults. Am J Gastroenterol 2009;104:828-833.

25. Aalberse RC, Platts-Mills TA, Rispens T. The Developmental History of IgE and IgG4 Antibodies in Relation to Atopy, Eosinophilic Esophagitis, and the Modified TH2 Response. Curr Allergy Asthma Rep 2016;16:45 doi:10.1007/s11882-016-0621-x

26. Litosh VA, Rochman M, Rymer JK, Porollo A, Kottyan LC, Rothenberg ME. Calpain-14 and its association with eosinophilic esophagitis. J Allergy Clin Immunol 2017;139:1762-1771.e7. doi:10.1016/j. jaci.2016.09.027

27. Rothenberg ME, Spergel JM, Sherrill JD, et al. Common variants at 5 q22 associate with pediatric eosinophilic esophagitis. Nat Genet 2010;42:289-291. doi:10.1038/ng.547

28. Kottyan LC, Maddox A, Braxton JR, et al. Genetic variants at the 16 p13 locus confer risk for eosinophilic esophagitis. Genes Immun 2019;20:281-292. doi:10.1038/s41435-018-0034-z

29. Jensen ET, Dellon ES. Environmental factors and eosinophilic esophagitis. J Allergy Clin Immunol 2018;142:32-40. doi:10.1016/j. jaci.2018.04.015

30. Kinoshita Y, Oouchi S, Fujisawa T. Eosinophilic gastrointestinal diseases - Pathogenesis, diagnosis, and treatment. Allergol Int 2019;68:420-429. doi:10.1016/j.alit.2019.03.003

31. Blanchard C, Mingler MK, Vicario M, et al. IL-13 involvement in eosinophilic esophagitis:Transcriptome analysis and reversibility with glucocorticoids. J Allergy Clin Immunol 2007;120:1292-1300. doi:10.1016/j.jaci.2007.10.024

32. Kinoshita $\mathrm{Y}$, Ishimura N, Oshima N, et al. Recent Progress in the Research of Eosinophilic Esophagitis and Gastroenteritis. Digestion 2016;93:7-12. doi:10.1159/000441668
33. Spechler SJ, Konda V, Souza R. Can Eosinophilic Esophagitis Cause Achalasia and Other Esophageal Motility Disorders? Am J Gastroenterol 2018;113:1594-1599. doi:10.1038/s41395-018-0240-3

34. O'Shea KM, Aceves SS, Dellon ES, et al. Pathophysiology of Eosinophilic Esophagitis. Gastroenterology 2018;154:333-345. doi:10.1053/j. gastro.2017.06.065

35. Spechler SJ. Eosinophilic esophagitis: novel concepts regarding pathogenesis and clinical manifestations. J Gastroenterol 2019;54:837844. doi:10.1007/s00535-019-01604-7

36. Merwat SN, Spechler SJ. Might the use of acid-suppressive medications predispose to the development of eosinophilic esophagitis? Am J Gastroenterol 2009;104:1897-1902.

37. Lanas A. We Are Using Too Many PPIs, and We Need to Stop: A European Perspective. Am J Gastroenterol 2016;111:1085-1086. doi: 10.1038/ajg.2016.166

38. Lyles J, Rothenberg M. Role of genetics, environment, and their interactions in the pathogenesis of eosinophilic esophagitis. Curr Opin Immunol 2019;60:46-53. doi:10.1016/j.coi.2019.04.004

39. Muñoz-Mendoza D, Chapa-Rodríguez A, Bahna SL. Eosinophilic Esophagitis Clinical Manifestations and Differential Diagnosis. Clin Rev Allergy Immunol 2018;55:7-18. doi:10.1007/s12016-017-8663-y

40. Paquet B, Bégin P, Paradis L, Drouin E, Des Roches A. High rate of failure to thrive in a pediatric cohort with eosinophilic esophagitis. Ann Allergy Asthma Immunol 2016;116:73-74.e1. doi:10.1016/j.anai.2015.09.015

41. Assaad AH, Putnam PE, Collins MH, et al. Pediatric patients with eosinophilic esophagitis: An 8-year follow-up. J Allergy Clin Immunol 2007;119:731-738. doi:10.1016/j.jaci.2006.10.044

42. Ettyreddy AR, Sink JR, Georg MW, Kitsko DJ, Simons JP. Association between Eosinophilic Esophagitis and Esophageal Food Impaction in the Pediatric Population. Otolaryngol Head Neck Surg 2018;159:750754. doi:10.1177/0194599818779049

43. Remedios M, Campbell C, Jones DM, Kerlin P. Eosinophilic esophagitis in adults: clinical, endoscopic, histologic findings, and response to treatment with fluticasone propionate. Gastrointest Endosc 2006;63:312. doi:10.1016/j.gie.2005.07.049

44. Dellon ES, Gibbs WB, Fritchie KJ, et al. Clinical, Endoscopic, and Histologic Findings Distinguish Eosinophilic Esophagitis From Gastroesophageal Reflux Disease. Clin Gastroenterol Hepatol 2009;7:1305-1313. doi:10.1016/j.cgh.2009.08.030

45. Mackenzie SH, Go M, Chadwick B, et al. Eosinophilic oesophagitis in patients presenting with dysphagia - A prospective analysis. Aliment Pharmacol Ther 2008;28:1140-1146. doi:10.1111/j.13652036.2008.03795.x

46. Ishimura N, Shimura S, Jiao D, et al. Clinical features of eosinophilic esophagitis:Differences between Asian and Western populations. J Gastroenterol Hepatol 2015;30 Suppl 1:71-77. doi:10.1111/jgh.12746

47. Veerappan GR, Perry JL, Duncan TJ, et al. Prevalence of Eosinophilic Esophagitis in an Adult Population Undergoing Upper Endoscopy: A Prospective Study. Clin Gastroenterol Hepatol 2009;7:420-426. doi:10.1016/j.cgh.2008.10.009

48. Jyonouchi S, Brown-Whitehorn TA, Spergel JM. Association of Eosinophilic Gastrointestinal Disorders with Other Atopic Disorders. Immunol Allergy Clin North Am 2009;29:85-97. doi:10.1016/j. iac.2008.09.008

49. Vermeulen BD, Bogte A, Verhagen MA, Pullens HJM, Siersema PD Management of eosinophilic esophagitis in daily clinical practice. Dis Esophagus 2018;31(2). doi:10.1093/dote/dox119

50. Harris RF, Menard-Katcher C, Atkins D, Furuta GT, Klinnert MD Psychosocial dysfunction in children and adolescents with eosinophilic 
esophagitis. J Pediatr Gastroenterol Nutr 2013;57:500-505. doi:10.1097/ MPG.0b013e31829ce5ad

51. Debrosse CW, Franciosi JP, King EC, et al. Long-term outcomes in pediatric-onset esophageal eosinophilia. J Allergy Clin Immunol 2011;128:132-138. doi:10.1016/j.jaci.2011.05.006

52. Mukkada V, Falk GW, Eichinger CS, King D, Todorova L, Shaheen NJ. Health-Related Quality of Life and Costs Associated With Eosinophilic Esophagitis: A Systematic Review. Clin Gastroenterol Hepatol 2018;16:495-503.e8. doi:10.1016/j.cgh.2017.06.036

53. Lee J, Huprich J, Kujath C, et al. Esophageal diameter is decreased in some patients with eosinophilic esophagitis and might increase with topical corticosteroid therapy. Clin Gastroenterol Hepatol 2012;10:481486. doi:10.1016/j.cgh.2011.12.042

54. Barrett C, Choksi Y, Vaezi MF. Mucosal impedance: a new approach to diagnosing gastroesophageal reflux disease and eosinophilic esophagitis. Curr Gastroenterol Rep 2018;20:33. doi:10.1007/s11894-018-0639-4

55. van Rhijn BD, Kessing BF, Smout AJ, Bredenoord AJ. Oesophageal baseline impedance values are decreased in patients with eosinophilic oesophagitis. United European Gastroenterol J 2013;1:242-248. doi:10.1177/2050640613496411

56. Farre R, Blondeau K, Clement D, et al. Evaluation of oesophageal mucosa integrity by the intraluminal impedance technique. Gut 2011;60:885892. doi:10.1136/gut.2010.233049

57. Krarup AL, Villadsen GE, Mejlgaard E, Olesen SS, Drewes AM, Funch-Jensen P. Acid hypersensitivity in patients with eosinophilic oesophagitis. Scand J Gastroenterol 2010;45:273-281. doi:10.3109/00365520903469931

58. Moawad FJ, Maydonovitch CL, Veerappan GR, Bassett JT, Lake JM, Wong RK. Esophageal Motor Disorders in Adults with Eosinophilic Esophagitis. Dig Dis Sci 2011;56:1427-1431. doi:10.1007/s10620-0111655-5

59. Roman S, Hirano I, Kwiatek MA, et al. Manometric features of eosinophilic esophagitis in esophageal pressure topography. Neurogastroenterol Motil 2011;23:208-214, e111. doi: 10.1111/j.13652982.2010.01633.x

60. Nennstiel S, Bajbouj M, Becker V, et al. High-resolution manometry in patients with eosinophilic esophagitis under topical steroid therapy-a prospective observational study (HIMEOS-study). Neurogastroenterol Motil 2016;28:599-607. doi:10.1111/nmo.12753

61. Surdea-Blaga T, David L, Botan EC, Dumitrascu DL. Achalasia-like Changes in Eosinophilic Esophagitis. J Gastrointestin Liver Dis 2019;28:146. doi:10.15403/jgld-171

62. Hruz P. Epidemiology of Eosinophilic Esophagitis. Dig Dis 2014;32:4047. doi:10.1159/000357008

63. Straumann A, Blanchard C, Radonjic-Hoesli S, et al. A new eosinophilic esophagitis (EoE)-like disease without tissue eosinophilia found in EoE families. Allergy 2016;71:889-900. doi:10.1111/all.12879

64. Kim HP, Vance RB, Shaheen NJ, Dellon ES. The Prevalence and Diagnostic Utility of Endoscopic Features of Eosinophilic Esophagitis: A Meta-analysis. Clin Gastroenterol Hepatol 2012;10:988-996.e5. doi: 10.1016/j.cgh.2012.04.019

65. Hirano I, Moy N, Heckman MG, Thomas CS, Gonsalves N, Achem SR. Endoscopic assessment of the oesophageal features of eosinophilic oesophagitis:validation of a novel classification and grading system. Gut 2013;62:489-495. doi:10.1136/gutjnl-2011-301817

66. Dellon ES, Cotton CC, Gebhart JH, et al. Accuracy of the Eosinophilic Esophagitis Endoscopic Reference Score in Diagnosis and Determining Response to Treatment. Clin Gastroenterol Hepatol 2016;14:31-39. doi:10.1016/j.cgh.2015.08.040
67. Schoepfer AM, Hirano I, Coslovsky M, et al. Variation in Endoscopic Activity Assessment and Endoscopy Score Validation in Adults With Eosinophilic Esophagitis. Clin Gastroenterol Hepatol 2019;17:14771488.e10. doi:10.1016/j.cgh.2018.11.032

68. Miehlke S, von Arnim U, Schlag C, et al. Clinical management of eosinophilic esophagitis - a nationwide survey among gastroenterologists in Germany. Z Gastroenterol 2019;57:745-752. doi:10.1055/a-0885-1963

69. Carlson DA, Hirano I. Narrow-caliber esophagus of eosinophilic esophagitis:difficult to define, resistant to remedy. Gastrointest Endosc 2016;83:1149-1150. doi:10.1016/j.gie.2016.01.034

70. Onbasi K, Sin AZ, Doganavsargil B, Onder GF, Bor S, Sebik F. Eosinophil infiltration of the oesophageal mucosa in patients with pollen allergy during the season. Clin Exp Allergy 2005;35:1423-1431. doi:10.1111/ j.1365-2222.2005.02351.x

71. Abe Y, Sasaki Y, Yagi M, Yaoita T, Nishise S, Ueno Y. Diagnosis and treatment of eosinophilic esophagitis in clinical practice. Clin J Gastroenterol 2017;10:87-102. doi:10.1007/s12328-017-0725-4

72. Shah A, Kagalwalla AF, Gonsalves N, Melin-Aldana H, Li BU, Hirano I. Histopathologic variability in children with eosinophilic esophagitis. Am J Gastroenterol 2009;104:716-721.

73. Katzka DA, Geno DM, Ravi A, et al. Accuracy, Safety, and Tolerability of Tissue Collection by Cytosponge vs Endoscopy for Evaluation of Eosinophilic Esophagitis. Clin Gastroenterol Hepatol 2015;13:77-83. e2. doi:10.1016/j.cgh.2014.06.026

74. Philpott H, Nandurkar S, Royce SG, Gibson PR. Ultrathin unsedated transnasal gastroscopy in monitoring eosinophilic esophagitis. J Gastroenterol Hepatol 2016;31:590-594. doi:10.1111/jgh.13173

75. Singla MB, Moawad FJ. An Overview of the Diagnosis and Management of Eosinophilic Esophagitis. Clin Transl Gastroenterol 2016;7:e155. doi:10.1038/ctg.2016.4

76. Anyane-Yeboa A, Wang W, Kavitt RT. The Role of Allergy Testing in Eosinophilic Esophagitis. Gastroenterol Hepatol (N Y) 2018;14:463-469.

77. Peterson KA, Byrne KR, Vinson LA, et al. Elemental Diet Induces Histologic Response in Adult Eosinophilic Esophagitis. Am J Gastroenterol 2013;108:759-766. doi:10.1038/ajg.2012.468

78. Arias Á, González-Cervera J, Tenias JM, Lucendo AJ. Efficacy of dietary interventions for inducing histologic remission in patients with eosinophilic esophagitis: A systematic review and meta-analysis. Gastroenterology 2014;146:1639-1648. doi:10.1053/j.gastro.2014.02.006

79. Spergel JM, Beausoleil JL, Mascarenhas M, Liacouras CA.The use of skin prick tests and patch tests to identify causative foods in eosinophilic esophagitis. J Allergy Clin Immunol 2002;109:363-368. doi:10.1067/ mai.2002.121458

80. Molina-Infante J, Martin-Noguerol E, Alvarado-Arenas M, PorcelCarreño SL, Jimenez-Timon S, Hernandez-Arbeiza FJ. Selective elimination diet based on skin testing has suboptimal efficacy for adult eosinophilic esophagitis. J Allergy Clin Immunol 2012;130:1200-1202. doi:10.1016/j.jaci.2012.06.027

81. Lucendo AJ, Arias Á, González-Cervera J, et al. Empiric 6-food elimination diet induced and maintained prolonged remission in patients with adult eosinophilic esophagitis: A prospective study on the food cause of the disease. J Allergy Clin Immunol 2013;131:797-804. doi:10.1016/j.jaci.2012.12.664

82. Gonsalves N, Yang GY, Doerfler B, Ritz S, Ditto AM, Hirano I. Elimination diet effectively treats eosinophilic esophagitis in adults;food reintroduction identifies causative factors. Gastroenterology 2012;142:1451-1459.e1. doi:10.1053/j.gastro.2012.03.001

83. Molina-Infante J, Arias A, Barrio J, Rodríguez-Sánchez J, SanchezCazalilla M, Lucendo AJ. Four-food group elimination diet for adult 
eosinophilic esophagitis:A prospective multicenter study. J Allergy Clin Immunol 2014;134:1093-1099.e1. doi:10.1016/j.jaci.2014.07.023

84. Molina-Infante J, Arias Á, Alcedo J, et al. Step-up empiric elimination diet for pediatric and adult eosinophilic esophagitis: The 2-4-6 study. J Allergy Clin Immunol 2018;141:1365-1372. doi:10.1016/j. jaci.2017.08.038

85. Wang R, Hirano I, Doerfler B, Zalewski A, Gonsalves N, Taft T. Assessing Adherence and Barriers to Long-Term Elimination Diet Therapy in Adults with Eosinophilic Esophagitis. Dig Dis Sci 2018;63:1756-1762. doi:10.1007/s10620-018-5045-0

86. Molina-Infante J, Lucendo AJ. Mistakes in eosinophilic oesophagitis and how to avoid them. UEG Education 2017;17:6-9.

87. Suzuki H, Hibi T. Novel effects other than antisecretory action and off-label use of proton pump inhibitors. Expert Opin Pharmacother 2005;6:59-67. doi:10.1517/14656566.6.1.59

88. Kedika RR, Souza RF, Spechler SJ. Potential anti-inflammatory effects of proton pump inhibitors:A review and discussion of the clinical implications. Dig Dis Sci 2009;54:2312-2317. doi:10.1007/s10620-0090951-9

89. Molina-Infante J, Rivas MD, Hernandez-Alonso M, et al. Proton pump inhibitor-responsive oesophageal eosinophilia correlates with downregulation of eotaxin- 3 and Th2 cytokines overexpression. Aliment Pharmacol Ther 2014;40:955-965. doi:10.1111/apt.12914

90. van Rhijn BD, Weijenborg PW, Verheij J, et al. Proton pump inhibitors partially restore mucosal integrity in patients with proton pump inhibitor-responsive esophageal eosinophilia but not eosinophilic esophagitis. Clin Gastroenterol Hepatol 2014;12:1815-1823.e2. doi:10.1016/j.cgh.2014.02.037

91. Van Malenstein H, Farré R, Sifrim D. Esophageal dilated intercellular spaces (DIS) and nonerosive reflux disease. Am J Gastroenterol 2008;103:1021-1028.

92. Vazquez-Elizondo G, Ngamruengphong S, Khrisna M, Devault KR, Talley NJ, Achem SR. The outcome of patients with oesophageal eosinophilic infiltration after an eight-week trial of a proton pump inhibitor. Aliment Pharmacol Ther 2013;38:1312-1319. doi:10.1111/ apt.12513

93. Moawad FJ, Veerappan GR, Dias JA, Baker TP, Maydonovitch CL, Wong RK. Randomized controlled trial comparing aerosolized swallowed fluticasone to esomeprazole for esophageal eosinophilia. Am J Gastroenterol 2013;108:366-372. doi:10.1038/ajg.2012.443

94. Molina-Infante J, Katzka DA, Gisbert JP. Review article:proton pump inhibitor therapy for suspected eosinophilic oesophagitis. Aliment Pharmacol Ther 2013;37:1157-1164. doi:10.1111/apt.12332

95. Lucendo AJ, Arias Á, Molina-Infante J. Efficacy of Proton Pump Inhibitor Drugs for Inducing Clinical and Histologic Remission in Patients With Symptomatic Esophageal Eosinophilia:A Systematic Review and Meta-Analysis. Clin Gastroenterol Hepatol 2016;14:13-22. e1. doi:10.1016/j.cgh.2015.07.041

96. Fujiwara Y, Hashimoto A, Uemura R, et al. Optimal biopsy protocol to evaluate histological effectiveness of proton pump inhibitor therapy in patients with eosinophilic esophagitis. Digestion 2019;100:64-71. doi:10.1159/000494253

97. Scarpignato C, Gatta L, Zullo A, et al. Effective and safe proton pump inhibitor therapy in acid-related diseases - A position paper addressing benefits and potential harms of acid suppression. BMC Med 2016;14:179. doi:10.1186/s12916-016-0718-Z

98. Lucendo AJ, Arias Á, González-Cervera J, et al. Dual response to dietary/ topical steroid and proton pump inhibitor therapy in adult patients with eosinophilic esophagitis. J Allergy Clin Immunol 2016;137:931-934.e2. doi:10.1016/j.jaci.2015.07.033

99. Sodikoff J, Hirano I. Proton pump inhibitor-responsive esophageal eosinophilia does not preclude food-responsive eosinophilic esophagitis. J Allergy Clin Immunol 2016;137:631-633. doi:10.1016/j. jaci.2015.07.008

100. Liacouras CA, Wenner WJ, Brown K, Ruchelli E. Primary eosinophilic esophagitis in children:Successful treatment with oral corticosteroids. J Pediatr Gastroenterol Nutr 1998;26:380-385. doi:10.1097/00005176199804000-00004

101. Schaefer ET, Fitzgerald JF, Molleston JP, et al. Comparison of Oral Prednisone and Topical Fluticasone in the Treatment of Eosinophilic Esophagitis: A Randomized Trial in Children. Clin Gastroenterol Hepatol 2008;6:165-173. doi:10.1016/j.cgh.2007.11.008

102. Murali AR, Gupta A, Attar BM, Ravi V, Koduru P. Topical steroids in eosinophilic esophagitis: Systematic review and meta-analysis of placebo-controlled randomized clinical trials. J Gastroenterol Hepatol 2016;31:1111-1119. doi:10.1111/jgh.13281

103. Sawas T, Dhalla S, Sayyar M, Pasricha PJ, Hernaez R. Systematic review with meta-analysis: Pharmacological interventions for eosinophilic oesophagitis. Aliment Pharmacol Ther 2015;41:797-806. doi:10.1111/ apt.13147

104. Chuang MY, Chinnaratha MA, Hancock DG, et al. Topical Steroid Therapy for the Treatment of Eosinophilic Esophagitis (EoE): A Systematic Review and Meta-Analysis. Clin Transl Gastroenterol 2015;6:e82. doi:10.1038/ctg.2015.9

105. Dellon ES, Sheikh A, Speck O, et al. Viscous topical is more effective than nebulized steroid therapy for patients with eosinophilic esophagitis. Gastroenterology 2012;143:321-324.e1. doi:10.1053/j. gastro.2012.04.049

106. Miehlke S, Hruz P, Vieth M, et al. A randomised, double-blind trial comparing budesonide formulations and dosages for shortterm treatment of eosinophilic oesophagitis. Gut 2016;65:390-399. doi:10.1136/gutjnl-2014-308815

107. Straumann A, Conus S, Degen L, et al. Long-term budesonide maintenance treatment is partially effective for patients with eosinophilic esophagitis. Clin Gastroenterol Hepatol 2011;9:400-409. e1. doi:10.1016/j.cgh.2011.01.017

108. Andreae DA, Hanna MG, Magid MS, et al. Swallowed Fluticasone Propionate Is an Effective Long-Term Maintenance Therapy for Children With Eosinophilic Esophagitis. Am J Gastroenterol 2016;111:1187-1197. doi:10.1038/ajg.2016.238

109. Albert D, Heifert TA, Min SB, et al. Comparisons of Fluticasone to Budesonide in the Treatment of Eosinophilic Esophagitis. Dig Dis Sci 2016;61:1996-2001. doi:10.1007/s10620-016-4110-9

110. Schroeder S, Fleischer DM, Masterson JC, Gelfand E, Furuta GT, Atkins D. Successful treatment of eosinophilic esophagitis with ciclesonide. J Allergy Clin Immunol 2012;129:1419-1421. doi:10.1016/j.jaci.2012.03.007

111. Mukker JK, Singh RSP, Derendorf H. Ciclesonide: A Pro-Soft Drug Approach for Mitigation of Side Effects of Inhaled Corticosteroids. J Pharm Sci 2016;105:2509-2514. doi:10.1016/j.xphs.2016.05.004

112. Lucendo AJ, Molina-Infante J. Esophageal dilation in eosinophilic esophagitis:risks, benefits, and when to do it. Curr Opin Gastroenterol 2018;34:226-232. doi:10.1097/MOG.0000000000000442

113. Eluri S, Runge TM, Cotton CC, et al. The extremely narrow-caliber esophagus is a treatment-resistant subphenotype of eosinophilic esophagitis. Gastrointest Endosc 2016;83:1142-1148. doi:10.1016/j. gie.2015.11.019 
114. Leigh LY, Spergel JM. An in-depth characterization of a large cohort of adult patients with eosinophilic esophagitis. Ann Allergy Asthma Immunol 2019;122:65-72.e1. doi:10.1016/j.anai.2018.09.452

115. Katzka DA. Esophageal Dilation as the Primary Treatment for Eosinophilic Esophagitis. Gastroenterol Hepatol (N Y) 2019;15:320-322.

116. Carlson DA, Hirano I, Zalewski A, Gonsalves N, Lin Z, Pandolfino JE. Improvement in Esophageal Distensibility in Response to Medical and Diet Therapy in Eosinophilic Esophagitis. Clin Transl Gastroenterol 2017;8:e119. doi:10.1038/ctg.2017.47

117. Arias-González L, Rey-Iborra E, Ruiz-Ponce M, Laserna-Mendieta EJ, Arias Á, Lucendo AJ. Esophageal perforation in eosinophilic esophagitis: A systematic review on clinical presentation, management and outcomes. Dig Liver Dis 2019. doi:10.1016/j.dld.2019.10.019

118. Moawad FJ, Cheatham JG, Dezee KJ. Meta-analysis: The safety and efficacy of dilation in eosinophilic oesophagitis. Aliment Pharmacol Ther 2013;38:713-720. doi:10.1111/apt.12438

119. Moawad FJ, Molina-Infante J, Lucendo AJ, Cantrell SE, Tmanova L, Douglas KM. Systematic review with meta-analysis: endoscopic dilation is highly effective and safe children and adults with eosinophilic oesophagitis. Aliment Pharmacol Ther 2017;46:96-105. doi:10.1111/apt.14123

120. Netzer P, Gschossmann JM, Straumann A, Sendensky A, Weimann R, Schoepfer AM. Corticosteroid-dependent eosinophilic oesophagitis:
Azathioprine and 6-mercaptopurine can induce and maintain long-term remission. Eur J Gastroenterol Hepatol 2007;19:865-869. doi:10.1097/ MEG.0b013e32825a6ab4

121. Lucendo AJ. Pharmacological treatments for eosinophilic esophagitis: current options and emerging therapies. Expert Rev Clin Immunol 2020;16:93-77. doi:10.1080/1744666X.2019.1705784

122. Straumann A, Conus S, Grzonka P, et al. Anti-interleukin-5 antibody treatment (mepolizumab) in active eosinophilic oesophagitis: a randomised, placebo-controlled, double-blind trial. Gut 2010;59:21-30. doi:10.1136/gut.2009.178558

123. Spergel JM, Rothenberg ME, Collins MH, et al. Reslizumab in children and adolescents with eosinophilic esophagitis: Results of a doubleblind, randomized, placebo-controlled trial. J Allergy Clin Immunol 2012;129:456-463.e3. doi:10.1016/j.jaci.2011.11.044

124. Clayton F, Fang JC, Gleich GJ, et al. Eosinophilic esophagitis in adults is associated with IgG4 and not mediated by IgE. Gastroenterology 2014;147:602-609. doi:10.1053/j.gastro.2014.05.036

125. Hirano I, Collins MH, Assouline-Dayan Y, et al. RPC4046, a Monoclonal Antibody Against IL13, Reduces Histologic and Endoscopic Activity in Patients With Eosinophilic Esophagitis. Gastroenterology 2019;156:592-603.e10. doi:10.1053/j. gastro.2018.10.051 